\title{
ESTETIKA FORMALIS FILM POHON PENGHUJAN SUTRADARA ANDRA FEMBRIARTO
}

\author{
Naafi Nur Rohma \\ Mahasiswa Minat Pengkajian Seni Film \\ Program Pascasarjana S-2 Penciptaan dan Pengkajian Seni, ISI Surakarta \\ No.Hp.:088216545321,E-mail: naafinurrohma@gmail.com \\ Jl. Ki Hadjar Dewantara No. 19, Jebres, Sutakarta 57126 \\ Matius Ali \\ Dosen Film Institut Kesenian Jakarta
}

\begin{abstract}
Abstrak
Penelitian berjudul "Estetika Formalis Film Pohon Penghujan Sutradara Andra Fembriarto" ini menggunakan metode penelitian kualitatif, pendekatan estetika formalis Sergei Eisenstein, dan teori estetika formalis Sergei Eisenstein. Adapun tujuan dari penelitian adalah untuk mengetahui estetika formalis dari film Pohon Penghujan sehingga dapat diketahui makna di balik film Pohon Penghujan. Permasalahan yang muncul dalam penelitian adalah estetika formalis dalam film Pohon Penghujan Sutradara Andra Fembriarto. Analisis yang dilakukan adalah analisis interpretasi pendekatan estetika formalis Sergei Eisenstein, yaitu mise-en-scene, sinematografi, montase, dan suara. Hasil yang didapatkan dalam penelitian adalah terpilihnya empat adegan berdasarkan tingkat dramatik film dan makna di balik keempat adegan tersebut.
\end{abstract}

Kata Kunci: estetika, formalis, Sergei Eisenstein, Pohon Penghujan

\begin{abstract}
Formalist Aesthetics of Pohon Penghujan Film Directed by Andra Fembrianto. The research entitled Formalist Aesthetics of Rainy Tree Film directed by Andra Fembriarto uses method of qualitative research, formalist aesthetics approach and Sergei Eisenstein formalist aesthetics theory. The aim of this research is to find out the formalist aesthetic value from the film of Pohon Penghujan to see the meaning beyond. The main problems that arise in this research is formalist aesthetics of Rainy Tree Film directed by Andra Fembriarto. The analysis conducted is the interpretative analysis using the formalist aesthetic approach by Sergei Eisenstein, which are mis-en-scene, cinematography, montage, and sound. The result of this research is that four scenes are selected in accord with the dramatic stage of the film and the meaning beyond those four scenes.
\end{abstract}

Keywords: aesthetics, formalist, Sergei Eisenstein, Pohon Penghujan

\section{PENDAHULUAN}

Banyak buku dan penelitian yang membahas film, tetapi tidak banyak buku dan penelitian yang membahas estetika formalis film. Sedikitnya literatur buku berbahasa Indonesia yang dapat dijadikan referensi mengenai estetika formalis film membuat kegelisahan tersendiri bagi peneliti. Hal ini membuat peneliti tertarik untuk meneliti estetika formalis film dalam film.
Adapun objek kajian dalam penelitian adalah film Pohon Penghujan, yaitu sebuah karya audiovisual yang telah berhasil meraih beberapa penghargaan. Salah satunya penghargaan Bay Area International Children's Film Festival di San Fransisco. Film Pohon Penghujan memiliki durasi tayang empat belas menit. Menceritakan keberadaan pohon penghujan dan kisah persaudaraan antara Arga dan Nanay. 
Arga dan Nanay telah lama berpisah. Arga diceritakan sebagai seorang kakak yang telah lama merantau ke negeri tetangga sehingga jarang pulang. Suatu hari, Arga pulang ke kampung halamannya. Dia telah melupakan teman-teman bahkan keluarganya. Suatu hari dia pergi ke tempat keberadaan pohon penghujan. Pohon penghujan itu tumbuh di antara gedung-gedung pencakar langit. Pohon itu mengeluarkan air dari daun-daunnya. Arga duduk di bawah pohon sambil membaca buku berjudul Tapak Air.

Nanay diam-diam mengikuti Arga dan mengganggunya. Berbagai cara dilakukanNanay, antara lain dengan menggunakan pengeras suara yang dikeluarkan dari tas kecil yang dibawanya, membunyikan alat musik drum dan gitar listrik dengan sangat keras, memberhentikan hujan dengan menancapkan lombok ke tanah dan membacakan mantera, memanah buah yang tumbuh di pohon itu sehingga membuat payung Arga rusak. Semua yang dilakukan Nanay membuat Arga marah besar. Mereka bertengkar dan kehujanan di bawah pohon. Nanay mengungkapkan rasa rindunya kepada Arga. Setelah itu Arga menyadari sikapnya yang salah kepada adiknya. Mereka pun kembali akur. Arga menceritakan akhir bahagia dari kisah buku yang dibacanya kepada Nanay lalu mereka pulang. Saat mereka meninggalkan tempat itu, muncul pelangi di sekitar pohon penghujan.

Mempelajari bentuk sebuah karya seni sama dengan melakukan sebuah studi estetika. Begitu juga dengan mempelajari bentuk film, maka sama dengan melakukan studi estetika film. Hal ini didukung dengan pernyataan, bahwa estetika merupakan refleksi atas fenomena makna yang dianggap sebagai sebuah fenomena artistik (Aumont, Bergala, Marie, \& Vernet, 1992). Berdasarkan pernyataan tersebut maka estetika merupakan sebuah studi tentang makna yang kemudian dianggap sebagai sebuah pesan artistik yang muncul pada sebuah karya seni.

Estetika film adalah studi film sebagai sebuah seni dan sebagai sebuah pesanartistic (Aumont et al., 1992). Berdasarkan pernyataan tersebut dapat disimpulkan bahwa film memproduksi banyak makna di dalam serangkaian adegan dari awal sampai akhir yang bertujuan untuk menyampaikan pesan kepada penikmat atau penonton film sehingga makna-makna yang muncul secara eksplisit dan implisit dianggap sebagai sebuah pesan artistik.

Melalui estetika film dapat diketahui bahwa teori-teori film dan pendekatan film diklasifikasikan menjadi dua, yaitu teori film formalis dan teori realis. Hal ini didukung dengan pernyataan berikut.

Teori formalis melihat film dari konstruksi dan komposisi film, sedangkan teori realis melihat film berdasarkan kemampuan film untuk menawarkan sebuah pandangan yang tak terjangkau atau realitas yang tidak termediasi. Dengan kata lain, formalis berfokus pada artifisial film, sedangkan realis berfokus pada semi transparansi media filmis, yang seolah-olah membawa penonton menjadi saksi langsung. Berdasarkan klasifikasi ini, tokoh-tokoh seperti Sergei Eisenstein, Rudolfh Arnheim, Formalis Rusia dan Neo-Formalis Amerika termasuk dalam konstruksi buatan film (formalis), sedangkan sisi lawannya adalah Bella Balazs, Siegfried Kracauer dan Andre Bazin di bawah label realisme ontologis (Elsaesser \& Hagener, 2010).

Berdasarkan pernyataan tersebut dapat disimpulkan bahwa teori formalis memfokuskan pada konstruksi dan komposisi film. Oleh sebab itu para filmmaker formalis lebih mementingkan gaya dan desain artistik.

Film Pohon Penghujan merupakan hasil dari konstruksi dan komposisi dari sutradara Andra Fembriarto untuk menyampaikan pesan 
kepada penontonnya. Film Pohon Penghujan merupakan film yang dibuat untuk tujuan tertentu. Kreativitas para filmmaker dituangkan di dalam naskah, mengkonstruksi serangkaian scene, mengatur pemain sekaligus melakukan perekaman. Editing dilakukan setelah proses perekaman, mengatur ritme, menyusun ulang gambar, membenturkan shot satu dengan yang lain dari hasil perekaman, memberikan efek pada scene yang dikonstruksi sehingga film Pohon Penghujan memiliki pesan gambar yang tersampaikan kepada penontonnya.

Pemain Arga, Nanay, dan sebuah scene pohon dalam film Pohon Penghujan merupakan satu kesatuan utuh dari serangkaian adegan yang dikonstruksi dan saling terkait. Melalui film Pohon Penghujan, Andra Fembriarto mengundang penonton untuk menggunakan imajinasinya dengan harapan, bahwa penonton dapat menciptakan pengalaman sendiri atas cerita yang disampaikan melalui filmnya.

Untuk mengetahui estetika formalis film Pohon Penghujan diperlukan analisis estetika formalis Sergei Eisenstein. Adapun teori dari Estetika Formalis Sergei Eisenstein sebagai berikut.

\section{Estetika Formalis Sergei Eisenstein}

\section{1) Mise-en-scene}

Sergei Eisenstein menyebutnya sebagai sebuah kelahiran dari konsep miseen-cadre, yaitu komposisi gambar dari shotshot yang saling terkait dalam sebuah urutan montase. Pada pertunjukan teater, konsep mise-en-cadre disebut dengan konsep mise-enscene, yaitu hubungan timbal balik dari orangorang dalam aksinya atau dalam permainannya. Selanjutnya, penyebutan mise-en-cadre lebih dikenal secara umum dalam istilah film sebagai mise-en-scene (Eisenstein, 1957).
Mise-en-scene diaplikasikan pertama kali dalam praktik mengarahkan drama teater (Bordwell \& Thompson, 1950). Istilah miseen-scene digunakan pula dalam film sebagai kontrol sutradara atas apa yang ditampilkan dalam frame film. Mise-en-scene meliputi pula aspek-aspek: setting, kostum dan tata rias, pencahayaan dan pergerakan pemain (Bordwell \& Thompson, 1950).

a. Setting

Setting adalah pengaturan keseluruhan latar lengkap dengan segala propertinya (Bordwell \& Thompson, 1950). Para pembuat film Pohon Penghujan membuat pengaturan latar cerita yang tampak pada permukaan layar senyata mungkin sehingga dapat meyakinkan penonton bahwa kejadian tersebut benar-benar terjadi sesuai dengan isi cerita filmnya.

Setting film bisa berasal ke permukaan; itu membutuhkan tidak hanya sebuah wadah untuk peristiwa atau kejadian-kejadian manusia tetapi bisa secara dinamis sesuai cerita. Pada film Ivan the Terrible, Sergei Eisenstein bebas mendekorasi istana Tsar untuk menyelaraskan dengan pencahayaan, kostum, dan gerakan tokoh, sehingga tampak karakter merangkak melalui pintu yang menyerupai lubang tikus dan berdiri beku sebelum mural alegori (Bordwell \& Thompson, 1950).

Pernyataan tersebutmenginformasikan bahwa setting sangat penting di dalam film. Hal itu dikarenakan setting bahwa sebuah adegan dapat terasa hidup apabila setting sesuai dengan isi cerita. 
b. Tata Rias dan kostum

Tata rias dan kostum memiliki fungsi yang sama seperti setting untuk mendukung bangunan konsep film (Bordwell \& Thompson, 1950).

Melalui film Ivan the Terrible, Sergei Eisenstein sangat berhatihati mengenai kostum, disesuaikan dengana warna-warnanya yang lain, tekstur-tekstur yang lain dan gerakan lainnya. Satu shot dari film Ivan the Terribel dan lawannya memberikan kostum jubah plastik pada mereka dan dinamis (Bordwell \& Thompson, 1950).

Kostum yang dipakai oleh para pemain memiliki peran penting dan menyesuaikan dengan isi cerita film Pohon Penghujan. Selain itu, melalui tata rias dan kostum dapat diketahui strata sosial karakter tokoh di dalam film Pohon Penghujan.

c. Pencahayaan

Cahaya di dalam film berfungsi sebagai pembentuk dimensi ruang. Film merupakan hasil manipulasi cahaya. Cahaya menjadi unsur yang mendukung pembentukan suasana dalam film.

Sisi yang bercahaya dan sisi yang gelap dalam frame membantu secara keseluruhan dari masing-masing shot dan memandu mengarahkan perhatian kita kepada objek dan aksinya (Bordwell \& Thompson, 1950).

d. Pemain serta Pergerakannya

Akting dari para pelaku cerita Pohon Penghujan sangat penting. Hal ini disebabkan bahwa kunci utama dari film adalah akting dari pelaku cerita karena melalui akting para aktor dapat meyakinkan penonton bahwa karakter yang dibawakan pelaku cerita itu benarbenar ada.

Para pembuat film juga harus memperhatikan pemain serta pergerakan pemain dalam miseen-scene.Pemain menjadi pelaku cerita yang paling penting untuk menggerakkan sebuah cerita. Pelaku cerita tidak harus manusia tetapi bisa juga binatang (Bordwell \& Thompson, 1950).

2) Sinematografi

Sinematografi Sergei Eisenstein terinspirasi dari tulisan-tulisan Jepang yang berbentuk hieroglyp. Shot diibaratkan seperti satu hieroglyp. Hal ini didukung dengan pernyataan sebagai berikut.

Hieroglyp-hieroglyp yang terpisah jika digabungkan akan membentuk ideogram. Kombinasi atau gabungan kedua hieroglyph tersebut akan mencapai sesuatu, yaitu hieroglyph yang lain. Misalnya gambar mulut digabungkan dengan gambar seorang anak kecil maka maknanya adalah berteriak; Seekor Anjing + Mulut = Menggonggong; Seeokor Burung + Mulut = Menyanyi (Eisenstein, 1957).

Pernyataan tersebut dapat diinformasikan, bahwa jika gambar-gambar itu diterapkan di dalam film, kedua dua gambar itu disebut dengan shot-shot. Shot-shot yang dikombinasikan merupakan eleman dasar prinsip dari montase.

Setiap shot memiliki motivasi. Adapun motivasi shot ditentukan oleh angle dan jarak. 
Angle: the straight on angle, the high angle dan the low angle. Jarak: extreme long shot, long shot, medium long shot, medium shot, medium close-up, close up, extreme close-up (Bordwell \& Thompson, 1950).

\section{3) Montase}

Montase Sergei Eisenstein berbasis dari sebuah bahasa film, sinematik daripada kode verbal, dengan kesesuaiannya, bahkan kepentingan, sintaksis. Berdasarkan keterkaitan antara montase dengan dialektika dapat disimpulkan bahwa montase merupakan prinsip dialetika.

Dialektika adalah negativitas yang membawa kemajuan ke arah kebebasan yang lebih tinggi. Pola dasar dialektika adalah pola dialogis: saling menyangkal dan kemudian saling membenarkan dan memajukan (Ali, 2003).

Dari pernyataan Hegel tersebut dapat disimpulkan bahwa suatu momen yang bersifat positif adalah negatif. Hal ini disebabkan akan memancing penyangkalan dan penyangkalan itu harus disangkal. Setiap tesis memancing anti-tesis dan setiap anti-tesis akan menjadi tesis baru yang memancing anti-tesisnya lagi (Ali, 2003). Artinya, setiap tesis baru yang muncul sebagai hasil dari penyangkalan atau konflik antara tesis dan antitesis disebut dengan tesis baru atau sintesis (Ben-Shaul, 2007).

Dalam ranah seni, prinsip dialektik bersifat dinamis dan diwujudkan dalam 'konflik'. Arti konflik di sini adalah konflik intelektual, konflik ide, konflik rasional. Oleh sebab itu, konflik tidak perlu ditakuti. Penyangkalan terhadap penyangkalan adalah positivitas. Itu merupakan prinsip dari negativitas (Ali, 2003).
Prinsip dialektika Hegel dapat digambarkan dengan bagan berikut.

\begin{tabular}{|c|c|c|}
\hline Tesis & Antitesis & Sintesis \\
\hline $\begin{array}{c}\text { Seorang anak } \\
\text { kecil }\end{array}$ & Sebuah mulut & Berteriak \\
\hline
\end{tabular}

Tabel 1. Prinsip Dialektika Hegel

Sumber: Modifikasi Naafi Nur Rohma

Hubungan antara dialektika Hegel dengan montase Sergei Eisenstein adalah tabrakan (montage of collision). Sergei Eisenstein menyebutkan bahwa montase adalah konflik. Jika shot A ditabrakkan dengan shot B maka akan menghasilkan shot $\mathrm{AB}$ sebagai hasil konflik.

4) Suara

Suara juga muncul saat penonton menonton film. Suara menjadi relasi antara gambar dengan suara. Suara yang dimaksud adalah tidak hanya suara dialog antara dua tokoh dalam film Pohon Penghujan, tetapi juga suara-suara latar belakang, dan efek suara. Suara memiliki fungsi sebagai pendukung pembentukan emosi penoton saat melihat film. Dengan demikian, suara memiliki fungsi yang penting dalam film.

Suara adalah teknik film yang kuat karena beberapa alasan.Untuk satu hal, yakni membentuk rasa yang berbeda. Sergei Eisenstein menyebutnya "sinkronisasi indra" membuat sebuah irama atau kualitas ekspresif menyatukan gambar dan suara. Selain itu, suara dapat membentuk cara kita memandang dan menafsirkan gambar (Bordwell \& Thompson, 1950). 


\section{ANALISIS ESTETIKA FORMALIS SERGEI EISENSTEIN SUTRADARA ANDRA FEMBRIARTO}

\section{Adegan Pengantar Film Pohon Penghujan (Tesis)}
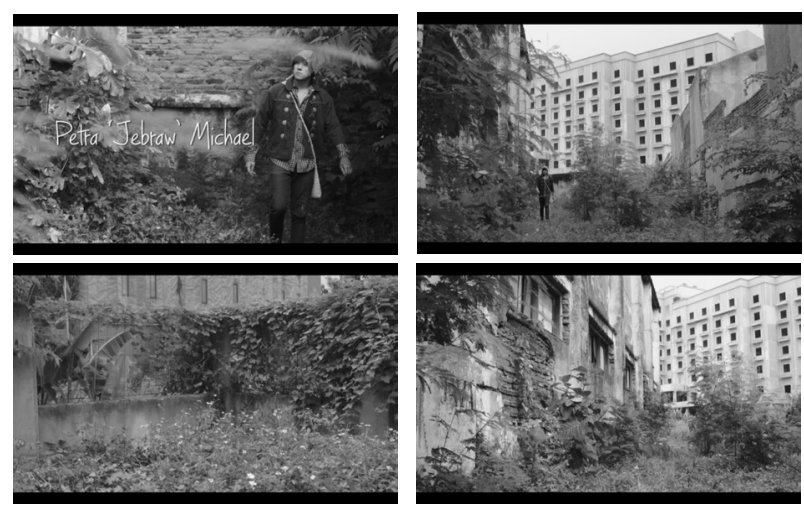

Gambar 1. Adegan Pengantar Film Pohon Penghujan (Sumber foto: capture film Pohon Penghujan timecode00.00.11-00.02.10)

\section{Deskripsi Adegan}

Adegan pengantar film Pohon Penghujan secara garis besar memiliki struktur atau komposisi film sebagai berikut

Suara kicauan burung mengiringi Arga yang sedang berjalan dengan santai dari balik dinding gedung. Sesekali dia memperhatikan dinding-dinding gedung yang rusak. Dia memakai baju, jaket, dan topi yang cenderung berwarna gelap. Tempat-tempat yang dilewatinya pun tampak sepi. Hanya ada gedung-gedung pencakar langit yang tampak tak terawat. Dinding-dindingnya sudah rusak dan kusam. Rumput-rumput serta ilalang tumbuh liar di antara pagar dan gedung-gedung. Langit nampak mendung. Arga berjalan melewati tempat-tempat tersebut dan semilir angin menerpa daun-daun ilalang di sekelilingnya.

\section{Analisis}

\section{1) Mise-en-scene}

Setting: suatu tempat yang berada di antara gedung pencakar langit tetapi jauh dari perkotaan. Gedung-gedung itu menjulang tinggi. Kedamaian divisualisasikan melalui tempat-tempat yang berbeda dengan suasana yang damai dan tidak ada satu orang pun tampak di tempat itu selain Arga. Melalui tempat-tempat yang ditunjukkan pada beberapa keempat shot di atas dapat diketahui bahwa tempat yang dituju Arga memang tempat yang jauh dari keramaian kota. Terlihat bahwa tempat tersebut jarang sekali dikunjungi orang.

Tata rias dan kostum: Kostum tokoh Arga adalah jaket warna biru tua, kemeja kotakkotak warna hitam, celana jeans, topi rajutan berwarna abu-abu, sepatu kets hitam, dan tas selempang kecil warna cokelat muda. Make up tokoh Arga dibuat senetral mungkin sehingga tokoh Arga seolah-olah tanpa memakai make up apa pun seperti dalam kehidupan sehari-hari. Melalui warna kostum yang dipakai Arga yang cenderung memiliki warna-warna gelap dapat diketahui karakter tokoh Arga, yakni pemurung, tenang, dan pendiam. Melalui kostum Arga dapat diketahui bahwa Arga berasal dari keluarga kelas menengah ke atas.

Pencahayaan: Pencahayaan pada serangkaian adegan di atas menggunakan pencahayaan yang natural. Artinya, memanfaatkan sinar matahari langsung sehingga adegan tampak natural. Bayangan yang terbentuk pada serangkaian adegan tokoh Arga tidak terlihat keras atau tajam seperti ketika matahari bersinar terang. Situasi yang ada dalam serangkaian adegan adalah situasi yang tenang dan mendung.

Pemain serta pergerakannya: Arga berjalan dengan santai tanpa menunjukkan ekspresi apa pun. Kadang-kadang dia menoleh ke arah kanan atau kiri. Melihat dinding-dinding gedung pencakar langit yang rusak. 


\section{2) Sinematografi}

Pada shot pertama, kamera bergerak secara tiltdown ${ }^{1}$ pelan. Durasi dari shot pertama adalah tujuh detik. Pergerakan kamera dari atas ke bawah terjadi sangat halus. Hal ini menunjukkan kepada penonton bahwa langit pada saat itu dalam keadaan mendung dan tenang.

Kamera bergerak ke bawah hingga berada pada posisi seperti mata memandang pada umumnya (straight on angle). Hal ini menunjukkan bahwa pada saat mendung ada seorang laki-laki bernama Arga sedang berjalan. Ditampakkan tokoh Arga berjalan ke depan mendekat ke arah kamera. Seolaholah Arga sedang berjalan ke arah penonton. Shot ini ditunjukkan dengan frame secara long shot ${ }^{2}$. Motivasi dari shot pertama adalah untuk menunjukkan latar belakang tempat dimana tokoh sedang berada serta suasana tempat itu.

Shot kedua, tampak secara medium long shot ${ }^{3}$ Arga berjalan keluar dari balik gedung yang tidak bercat. Dia menoleh ke kanan, melihat ke arah gedung yang telah rusak. Dindingdinding batu batanya telah runtuh. Kamera dalam keadaan diam dengan posisi seperti mata memandang pada umumnya (straight on angle).

Motivasi shot kedua menunjukkan bahwa Arga berjalan sambil melihat keadaan gedunggedung yang dilewatinya serta menunjukkan kepada penonton bahwa keadaan gedung itu telah rusak. Durasi shot kedua adalah lima detik, lebih cepat dari shot sebelumnya. Hal itu menunjukkan bahwa shot kedua tidak lebih penting dari shot pertama.
Shot ketiga, dan keempat diambil dengan frame long shot. Pada shot ketiga dan keempat di atas tidak menampakkan Arga, tetapi hanya tempat-tempat yang dimaksud oleh narator. Durasi shot ketiga dan keempat relatif sama, yaitu satu detik. Hal ini menunjukkan bahwa shot ini hanya bertujuan untuk menunjukkan tempat serta situasi saja. Selain itu, tempattempat ini juga menafsirkan kedamaian.

Secara sinematografi keempat shot di atas, yakni posisi kamera lebih dominan memakai posisi diam dengan sudut pandang mata pada umumnya.

\section{3) Montase}

Antara shot pertama sampai keempat diberikan transisi cut $^{4}$. Motivasi transisi yang diberikan antara shot pertama sampai keempat adalah menunjukkan kelanjutan atau kontinuitas shot.

Benturan antar-shot membangun dialektika Hegel, yakni kedamaian. Konflik yang dibangun di dalam serangkaian shot yakni tempat sepi cenderung tidak pernah dikunjungi orang dan tempat tidak terawat, namun hal itu menjadi positivitas bagi Arga. Arga memiliki tempat pribadi untuk menyendiri tanpa gangguan orang lain. Dia merasa nyaman dengan keberadaannya di tempat sepi itu.

\section{4) Suara}

Adegan diawali musik scoring bernada minor ${ }^{5}$ serta efek suara kicauan burung. Suasana damai itu pun membuat terdengar jelas suara

\footnotetext{
${ }^{1}$ Gerakan kamera yang berputar pada sumbu horizontal. Hanya kepala kamera yang berputar ke atas atau bawah. Seluruh kamera tidak berubah posisi. Layar, gerakan tilt menghasilkan kesan membuka gulungan atas ruang depan ke bawah atau bawah ke atas; lihat David Bordwell dan Kristin Thompson, Film Art, An Introduction, hal.195.

2 Tokoh terlihat namun latar belakang masih tampak lebih dominan; lihat David Bordwell dan Kristin Thompson, Film Art, An Introduction, hal. 191.

3 Tokoh tampak dari lutut ke atas; lihat David Bordwell dan Kristin Thompson, Film Art, An Introduction, hal. 191.

${ }^{4}$ Cara yang paling umum digunakan untuk menggabungkan dua shot: lihat David Bordwell dan Kristin Thompson, Film Art, An Introduction, hal. 219.

${ }^{5}$ Musik yang menunjukkan kesedihan, keprihatinan.
} 
rerumputan yang terinjak kaki disusul sebuah narasi yang muncul dibawakan oleh seorang narator. Narator membawakan narasi itu dengan intonasi rendah, pelan, dan berirama.

Shot kedua, narasi masih diiringi dengan musik scoring.Terdengar juga suara langkah kaki yang menginjak rerumputan menandakan suasana ketenangan serta kedamaian saat itu.

Pada shot ketiga dan keempat juga masih diiringi musik scoring. Efek suara seperti suara ambulan dan keramaian perkotaan yang terdengar sangat tipis. Efek suara yang terdengar membangun suasana bahwa keberadaan tempat-tempat itu memang di tengah keramaian perkotaan.

Secara keseluruhan analisis di atas mulai dari pergerakan tokoh, posisi kamera, pencahayaan, serta suara memengaruhi makna yang muncul dari serangkaian adegan pengantar. Ketidakadaan konflik dalam adegan, pergerakan kamera serta tokoh Arga yang berjalan pelan dan tenang, efek suara kicauan burung, musik scoring bernada minor serta pembawaan narator dengan intonasi nada rendah membangun rasa ketenangan serta kedamaian di tempatitu. Semilir angin yang menerpa dedaunan dan menerpa Arga membuat tempat itu terasa rimbun, sejuk dan nyaman seperti suasana di pedesaan yang damai pada pagi hari.

Adegan pertama sebagai adegan pengantar film Pohon Penghujan mampu membangun suasana damai dan tenang dalam adegan.

\section{Adegan Hujan sebagai Dinding Pemisah (Antitesis)}

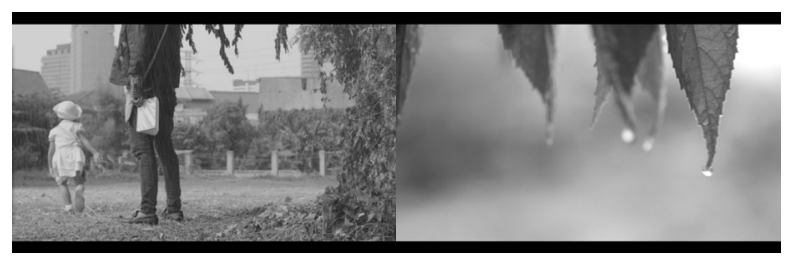

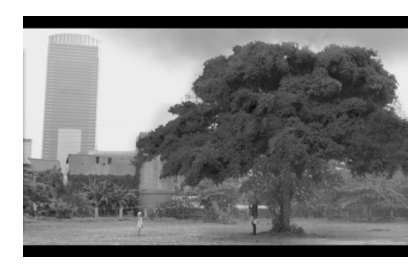

Gambar 2. Pohon Penghujan sebagai Dinding Pemisah (Sumber foto: capture film Pohon Penghujan timecode00.03.03-00.03.08)

\section{Deskripsi Adegan}

Arga dan Nanay berada di bawah sebuah pohon yang tumbuh di antara gedung-gedung pencakar langit. Daunnya rimbun dan hijau. Hujan turun tepat setelah Arga marah kepada Nanay. Seolah-olah mendukung suasana pada saat itu. Langit masih dalam keadaan mendung. Dedaunan mulai mengeluarkan air. Nanay yang semula berada di dekat Arga berlari. Sementara Arga tetap berdiri di tempat dengan membawa payungnya. Dia melihat Nanay berlari keluar dari area hujan. Nanay yang memakai baju dan topi warna kuning berdiri di luar area hujan menghadap ke arah Arga.

\section{Analisis}

\section{1) Mise-en-scene}

Setting: Adegan tersebut berada di bawah pohon penghujan. Pencahayan pada ketiga shot di atas lebih cenderung redup karena mendung. Tidak ada bayangan keras yang terbentuk pada tokoh Arga dan Nanay. Pergerakan Nanay pada shot kedua dan ketiga tampak lebih lincah dan riang daripada tokoh Arga. Sementara Arga memakai kostum yang sama dalam adegan sebelumnya.

Tata rias dan kostum yang dipakai Nanay adalah baju warna kuning, topi berwarna kuning, sepatu berwarna cokelat, kaos kaki warna putih, dan tas selempang kecil berwarna oranye. Make up Nanay terlihat natural. Warna kostum Nanay yang bertolak belakang dengan warna kostum Arga dapat ditafsirkan bahwa 
mereka juga memiliki karakter yang bertolak belakang. Warna kostum Nanay yang cenderung kuning menandakan bahwa Nanay memiliki karakter periang dan ceria.

Kostum tokoh Arga adalah jaket warna biru tua, kemeja kotak-kotak warna hitam, celana jeans, topi rajutan berwarna abu-abu, sepatu kets hitam, dan tas selempang kecil warna cokelat muda. Make up tokoh Arga dibuat senetral mungkin sehingga tokoh Arga seolah-olah tanpa memakai make up apa pun seperti dalam kehidupan sehari-hari.

Pencahayaan: Pencahayaan dalam serangkaian adegan di atas menggunakan pencahayaan yang natural, yakni dengan memanfaatkan sinar matahari langsung. Dalam adegan ini tidak tampak matahari bersinar. Suasana langit terlihat mendung sehingga bayangan yang terbentuk dalam serangkaian adegan tokoh Arga tidak terlihat keras atau tajam seperti ketika matahari bersinar terang. Situasi yang ada dalam serangkaian adegan adalah situasi yang tenang.

Pemain serta pergerakannya: Arga yang semula duduk sambil membaca buku tampak marah kepada Nanay ketika Nanay mengganggunya. Dia berdiri dengan gerakan cepat dan membentak Nanay. Nanay dengan sigap berlari keluar dari area hujan dengan mengatakan "Yaaah!! Hujan!!” ada penyesalan dari nada suara Nanay ketika mengatakan "Yaa hujan!!" Hal ini disebabkan Nanay tidak dapat meneruskan obrolannya dengan Arga.

\section{2) Sinematografi}

Secara sinematografi dapat dilihat pada shot pertama tampak secara close up ujungujung dari dedaunan terdapat tetes-tetesan air. Lensa tampak memfokuskan pada dedaunan sehingga kedalaman shot terbentuk. Sementara latar belakang tampak blur sehingga pandangan mata penonton terfokus pada dedauanan. Durasi shot pertama adalah satu detik. Menunjukkan bahwa daun mengeluarkan air, menandakan bahwa hujan turun dari pohon itu. Diiringi dengan suara hujan. Transisi antara shot pertama dan kedua adalah cut.

Shot kedua tampak secara long shot Nanay menggerakkan tangannya ke atas, merasakan titik hujan membasahi telapak tangannya. Nanay segera berlari keluar dari area hujan sebagai gerakan refleksnya menghindari hujan. Sementara itu, Arga tetap berdiri di tempat itu.

Shot ketiga tampak secara extreme long shot Nanay keluar dari area hujan, sementara Arga masih berdiri dengan payungnya. Diiringi dengan dialog Nanay: "Yaaah!! Hujan!!" Shot ketiga lebih menunjukkan situasi pada saat itu. Durasi shot relatif sama dengan shot sebelumnya, yakni tiga detik.

Ketika Nanay mengatakan "Yaaah!! Hujan!!” dengan nada suara penuh penyesalan dan sambil bergerak lari keluar area hujan, dapat diinterpretasikan bahwa ada kesedihan dalam benak Nanay dikarenakan hujan membuat dia jauh dari Arga.

Melalui adegan pertama sampai pada adegan ketiga dapat ditafsirkan, bahwa kamera berada pada sudut pandang seperti orang ketiga yang memerhatikan kejadian antartokoh Nanay dan Arga atau disebut dengan sudut pandang objektif kamera. Kamera berada di belakang Arga berdiri. Disebabkan kamera memakai sudut pandang Nanay, membuat Arga tidak tampak secara keseluruhan. Durasi shot kedua adalah tiga detik. Menunjukkan reflek Nanay saat hujan turun. Diiringi dengan musik scoring dan suara hujan. 


\section{3) Montase}

Berdasarkan deskripsi di atas dapat dianalisis bahwa shot pertama merupakan tesis. Tesis menampakkan air yang menetes melalui daun pohon, seolah-olah menandakan bahwa hujan yang keluar dari pohon membawa energi negatif dari diri Arga. Keluarnya hujan seolaholah mengusir keberadaan Nanay supaya tidak mendekati Arga. Konflik persaudaraan antara Arga dan Nanay ditafsirkan pada shot kedua dan ketiga, saat pohon penghujan mengeluarkan hujan membuat Nanay tidak bisa melanjutkan komunikasinya terhadap Arga. Nanay harus keluar dari area hujan dikarenakan dia tidak membawa payung. Mereka berdiri berhadapan namun saling berjauhan.

Shot kedua merupakan antitesis. Arga marah kepada Nanay dengan membentaknya karena telah mengganggu Arga. Benturan antara shot pertama dan kedua menghasilkan shot ketiga sebagai sintesis, yakni Nanay menjauh dari Arga. Nanay pergi menjauh dari Arga sebagai sebuah tafsiran dari konflik hubungan persaudaraan Arga dan Nanay. Jika tidak ada konflik hubungan persaudaraan, Nanay akan ikut berteduh di payung Arga atau Arga akan meminta Nanay untuk berteduh dengannya. Sebaliknya, keadaan hubungan mereka sedang mengalami konflik sehingga berteduh di bawah payung milik Arga adalah suatu kemungkinan yang kecil bagi Nanay. Hal ini dikarenakan Arga dalam keadaan yang sedang tidak ingin diganggu oleh siapa pun bahkan Nanay. Jika Nanay berteduh di bawah payung Arga, akan menambah kemarahan Arga kepada Nanay. Nanay lebih memilih untuk pergi keluar dari area hujan demi menyelamatkan diri dari guyuran hujan.

\section{4) Suara}

KemarahanArga disusul dengan turunnya hujan deras. Suara hujan deras mengiringi situasi konflik antara Arga dan Nanay. Serangkaian adegan ini diiringi dengan music scoring bernada minor sehingga menimbulkan suasana dan rasa simpati kepada tokoh Nanay.

Berdasarkan analisis interpretasi pendekatan estetika formalis Sergei Eisenstein tersebut didapatkan sebuah makna konflik hubungan persaudaraan antara Arga dan Nanay. Konflik persaudaraan Arga dan Nanay digambarkan melalui visualisasi shot-shot di atas. Serangkaian adegan dalam gambar menunjukkan bahwa hujan yang keluar dari pohon seperti dinding pemisah antara Arga dan Nanay. Hal itu dapat ditafsirkan sebagai sebuah makna adanya konflik hubungan persaudaraan Arga dan Nanay.

\section{SIMPULAN}

Hasil penelitian film Pohon Penghujan sutradara Andra Fembriarto sebagai berikut. Pertama adalah serangkaian adegan pengantar film sebagai tesis ditemukan makna kedamaian dan kedua adalah serangkaian adegan penyebab kekesalan Arga kepada Nanay sebagai antitesis ditemukan makna konflik hubungan persaudaraan Arga dan Nanay. Hasil dari analisis estetika formalis Sergei Eisenstein film Pohon Penghujan adalah dapat diketahui makna yang tersembunyi dibalik rangkaian adegan film Pohon Penghujan. Adapun makna yang ada di balik film Pohon Penghujan adalah makna kedamaian dan makna konflik atau kerenggangan hubungan Arga dan Nanay.

\section{KEPUSTAKAAN}

Ali, M. (2003). Estetika, Pengantar Filsafat Seni. Jakarta: Sanggar Luxor.

Aumont, J., Bergala, A., Marie, M., \& Vernet, M. (1992). Aesthetics of Film. USA: 
University of Texas Press.

Ben-Shaul, N. (2007). Film The Key Concepts.

New York: Berg.

Bordwell, D., \& Thompson, K. (1950). Film Art, An Introduction (8th ed.). New York: The McGraw-Hill.

Eisenstein, S. (1957). Film Form and The Film Sense. USA: Meredian Books.

Elsaesser, T., \& Hagener, M. (2010). Film Theory, An Introduction Through The Senses. New York: Routledge. 